\title{
Resveratrol shows neuronal and vascular-protective effects in older, obese, streptozotocin-induced diabetic rats
}

\author{
Hnin Ei Phyu, Jordon Candice Irwin, Rebecca Kate Vella* and Andrew Stuart Fenning \\ School of Medical and Applied Sciences, Central Queensland University Australia, Bruce Highway, North Rockhampton, \\ Qld 4701, Australia \\ (Submitted 26 October 2015 - Final revision received 28 January 2016 - Accepted 17 February 2016 - First published online 8 April 2016)
}

\section{Abstract}

Diabetes-induced CVD is the most significant complication of prolonged hyperglycaemia. The aim of this study was to determine whether resveratrol, a polyphenol antioxidant compound, when administered at a dose that can be reasonably obtained through supplementation could prevent the development of cardiovascular complications in older, obese, diabetic rats. Diabetes was induced in 6-month old, obese, male Wistar rats via a single intravenous dose of streptozotocin $(65 \mathrm{mg} / \mathrm{kg})$. Randomly selected animals were administered resveratrol $(2 \mathrm{mg} / \mathrm{kg})$ via oral gavage daily for 8 weeks. Body weights, blood glucose levels, food intake and water consumption were monitored, and assessments of vascular reactivity, tactile allodynia and left ventricular function were performed. Resveratrol therapy significantly improved tactile allodynia and vascular contractile functionality in diabetic rats $(P<0.05)$. There were no significant changes in standardised vasorelaxation responses, plasma glucose concentrations, water consumption, body weight, left ventricular hypertrophy, kidney hypertrophy, heart rate or left ventricular compliance with resveratrol administration. Resveratrol-mediated improvements in vascular and nerve function in old, obese, diabetic rats were associated with its reported antioxidant effects. Resveratrol did not improve cardiac function nor mitigate the classic clinical symptoms of diabetes mellitus (i.e. hyperglycaemia, polydypsia and a failure to thrive). This suggests that supplementation with resveratrol at a dose achievable with commercially available supplements would not produce significant cardioprotective effects in people with diabetes mellitus.

Key words: Resveratrol: Type 1 diabetes: Age: Obesity: Streptozotocin rats

Diabetes mellitus (DM) is a chronic, metabolic disease in which insufficient or absent secretion of insulin impairs glucose uptake from the bloodstream causing hyperglycaemia ${ }^{(1-4)}$. Hyperglycaemia promotes oxidative stress via overproduction of reactive oxygen species (ROS) inducing lipid peroxidation, mitochondrial dysfunction, altered signal transduction, abnormal gene expression and cell apoptosis ${ }^{(1,5-10)}$. In turn, these chemical and metabolic changes manifest many of the severe complications common to individuals with DM, including renal failure, CVD, endothelial dysfunction, hyperalgesic pain (diabetic neuropathy) and blindness ${ }^{(6,11-13)}$. Diabetes-induced CVD is the most significant complication of prolonged hyperglycaemia and is estimated to be responsible for approximately $80 \%$ of deaths in people with $\mathrm{DM}^{(12,14,15)}$.

Considering the substantial role of oxidative stress in the aetiology of DM, nutritional antioxidant therapies have considerable potential as preventative agents against the development of secondary complications associated with this condition ${ }^{(16-19)}$. The polyphenolic phytoalexin resveratrol (3,5,4-trihydroxystilbene) is one such antioxidant compound. Resveratrol is found naturally in a variety of foods including grape skins, blueberries, cranberries, Polygonum cuspidatum (Japanese knot-weed), peanuts and red wines $^{(20-23)}$.

Numerous studies have reported the benefits of resveratrol administration in the treatment of various CVD including coronary artery disease, cardiac arrhythmias, myocardial infarction, heart failure and cardiac fibrosis ${ }^{(20-24)}$. The cardioprotective effects of resveratrol are mostly attributable to its antioxidant properties, particularly its free-radical scavenging capacity and ability to up-regulate the expression of endogenous antioxidant genes ${ }^{(25-27)}$. Resveratrol has also demonstrated antiinflammatory, anti-cancer, anti-ageing, anti-viral and antiplatelet effects ${ }^{(17,21,23,28-34)}$.

The health benefits of resveratrol, however, appear to be dose dependent. A prospective cohort study on 1270 Tuscans over the age of 65 years found that dietary resveratrol levels were not associated with CVD, inflammatory markers, cancer or a lower all-cause mortality risk $^{(35)}$. Conversely, studies prescribing

Abbreviations: DM, diabetes mellitus; Res, resveratrol; SBP, systolic blood pressure; STZ, streptozotocin; STZ + Res, streptozotocin-induced diabetic rats treated with resveratrol.

* Corresponding author: Dr R. K. Vella, email r.vella@cqu.edu.au 
resveratrol supplements have reported improvements in oxidative stress, systolic blood pressure (SBP) and blood glucose and cholesterol levels in both healthy individuals and patients with $\mathrm{DM}^{(36-38)}$. Accordingly, these findings indicate that supplementation with resveratrol may improve cardiovascular and oxidative stress outcomes, particularly in individuals with DM.

The streptozotocin (STZ) rat is one of the most utilised animal models in diabetes research with well over 18000 PubMed citations (counted in 2016). Typically, young adult rats (8-12 weeks of age when diabetes is induced) are used to investigate the complications of DM and its treatment ${ }^{(34,39,40)}$. Independently, older Wistar rats are known to develop the metabolic syndrome/insulin resistance with age as visceral and retroperitoneal fat mass increases ${ }^{(41,42)}$. Although the cardioprotective effects of resveratrol in younger STZ-induced diabetic rats have been investigated, there are limited data on its effectiveness in older, obese rats - a model that may be more representative of type $1 \mathrm{DM}$ with some aspects of type $2 \mathrm{DM}^{(43)}$. Accordingly, this study aimed to assess whether resveratrol, when administered at a dose that can be reasonably achieved using commercially available supplements, could prevent the development of diabetes-induced cardiovascular complications in old, obese, STZ-induced diabetic rats.

\section{Methods}

\section{Animal models and treatment regimen}

In all, thirty male Wistar (WIS) rats (obtained from the Animal Resource Centre, Perth, WA) were randomised to one of the following four treatment groups: control (WIS, $n$ 8), control treated with resveratrol (WIS + Res, $n$ 8), STZ-induced diabetic model (STZ, $n$ 7) and STZ-diabetic model treated with resveratrol (STZ + Res, $n$ 7). Treatments for all animals began once they had reached 6 months of age and had become obese (i.e. $>500 \mathrm{~g}=$ body mass consistent with Wistar fatty rats) ${ }^{(44)}$. Diabetes was induced by a single injection of STZ $(65 \mathrm{mg} / \mathrm{kg})$ into the femoral vein. Water consumption and body weights of all rats were assessed weekly. Animals that were hyperglycaemic ( $>15 \mathrm{mmol} / \mathrm{l})$ and exhibited polydipsia and a failure to thrive (i.e. weight loss) were considered to be diabetic. Insulin was not administered to any of the rats during the study. Resveratrol was delivered as a bolus dose of $2 \mathrm{mg} / \mathrm{kg}$ via oral gavage daily for 8 weeks. This dose was chosen as it can be easily achieved in humans using commercially available resveratrol supplements and has been used successfully in previous investigations with young rats ${ }^{(37,38,45-47)}$. Animals were housed in a constant $12 \mathrm{~h}$ light- $12 \mathrm{~h}$ dark cycle at a temperature of $22(\operatorname{SEM} 2)^{\circ} \mathrm{C}$ and were allowed access to water and food ad libitum. All experimental procedures involving animals were approved by the Animal Ethics Committee of Central Queensland University under guidelines from the National Medical Research Council of Australia.

\section{Assessment of neuropathic pain}

Tactile allodynia was assessed at the end of the treatment period using von Frey filaments. Filaments were applied to the plantar surface of the animal's hind paw in increasing tensile strength ( 3 through to $20 \mathrm{~g}$ ) until the chosen filament flexed or a brisk paw-withdrawal response was observed ${ }^{(39)}$. Only light touches were applied to prevent tissue damage, and if there was no response $20 \mathrm{~g}$ was recorded.

\section{Blood collection and haemodynamic and biochemical assessment}

Before euthanasia, animals were sedated and their heart rate (HR) and SBP were measured using tail cuff plethysmography (ADInstruments). HR and SBP measurements were performed in the same environment animals were housed in (temperature 22 (SEM 2$)^{\circ} \mathrm{C}$ ) with three recordings taken per measurement. Familiarisation sessions were run before collection of data to ensure that representative responses were measured. All rats were then euthanised via an intraperitoneal injection of sodium phenobarbitone $(100 \mathrm{mg} / \mathrm{kg})$ and heparinised (1000 U/100 g) intravenously into the right femoral vein. Blood samples were collected from the abdominal vena cava allowing for the assessment of plasma glucose levels using Precision Plus Blood Glucose Electrodes (Medisense, Abbott Laboratories). Wet mass measurements of the left ventricle, right ventricle and kidneys, as normalised to body mass, were also recorded.

\section{Assessment of vascular function}

Assessment of vascular reactivity was performed according to Vella et $a l^{(46)}$. Thoracic aortas with intact endothelium were carefully isolated and suspended within $25 \mathrm{ml}$ organ baths containing gassed $\left(\mathrm{O}_{2} \quad(95 \%) / \mathrm{CO}_{2} \quad(5 \%)\right)$ Tyrode's solution (all in $\mathrm{mm}$ concentrations: $\mathrm{NaCl} 136 \cdot 9, \mathrm{KCl} 5 \cdot 4, \mathrm{MgCl}_{2} 1.05$, $\mathrm{NaH}_{2} \mathrm{PO}_{4}$ 0.42, $\mathrm{NaHCO}_{3} 22 \cdot 6, \mathrm{CaCl}_{2} 1 \cdot 8$, glucose 5.5, ascorbic acid $0 \cdot 28$, EDTA $0 \cdot 1 ; \mathrm{pH}$ approximately $7 \cdot 4$ ). The aortic rings were set at a resting tension of $10 \mathrm{mN}$ and were allowed to equilibrate for $30 \mathrm{~min}$ before being exposed to cumulative concentrations of noradrenaline, acetylcholine and sodium nitroprusside. Doseresponse curves to acetylcholine and sodium nitroprusside were completed in the presence of a submaximal contraction to noradrenaline $\left(3 \times 10^{-6} \mathrm{M}\right.$ concentration). Any fluctuations in tension were measured using transducers and recorded using Chart software and PowerLab ${ }^{\circledR}$ data acquisition units.

\section{Assessment of left ventricular function}

Langendorff heart preparations were used to measure left ventricular function ${ }^{(46)}$. In short, hearts were isolated and perfused retrogradely via an aortic cannula with gassed $\left(\mathrm{O}_{2}(95 \%) / \mathrm{CO}_{2}\right.$ (5\%)) modified Krebs-Henseleit buffer (all in mm concentrations: $\mathrm{NaCl} 119 \cdot 1, \mathrm{KCl} 4 \cdot 75, \mathrm{MgSO}_{4} 1 \cdot 19, \mathrm{KH}_{2} \mathrm{PO}_{4} 1 \cdot 19, \mathrm{NaHCO}_{3} 25 \cdot 0$, glucose 11.0 and $\mathrm{CaCl}_{2} 2 \cdot 16$; $\mathrm{pH}$ approximately $7 \cdot 4$ ) and maintained at $37^{\circ} \mathrm{C}$ with a constant pressure of $100 \mathrm{mmHg}$. Isovolumic contractile left ventricular function was assessed by inserting a latex balloon catheter connected to a pressure transducer into the left ventricle. The balloon volume was adjusted to $0 \mathrm{mmHg}$ of diastolic pressure and hearts were paced at 250 beats/min using an artificial stimulation source. End-diastolic pressure was 
recorded for $3 \mathrm{~min}$ at $5 \mathrm{mmHg}$ increments over a range of 0-30 mmHg to allow for calculation of diastolic stiffness and left ventricular developed pressure. Contractile function was measured by calculating maximal and minimal $+d P / d t$ values together at a diastolic pressure of $10 \mathrm{mmHg}$.

\section{Drugs and chemicals}

Resveratrol, STZ, noradrenaline, acetylcholine and sodium nitroprusside were purchased from the Sigma Chemical Company. All serial dilutions of noradrenaline, acetylcholine and sodium nitroprusside were made using distilled water. Reagents and chemicals utilised in the preparation of buffers were of analytical grade and purchased from the Sigma Chemical Company and Thermo Fisher Scientific.

\section{Statistical analysis}

All data are presented as mean values with their standard errors.

The results were analysed using Student's independent samples $t$ test and a two-way ANOVA with Bonferroni post hoc tests where appropriate. All statistical analyses were performed using GraphPad Prism software version 3.0 for Windows (GraphPad Software, Inc.). Statistical significance was set at an $\alpha$ level of $P<0 \cdot 05$.

\section{Results}

\section{Biometric parameters}

Significant increases in blood glucose and water intake, in conjunction with an impaired ability to gain weight, confirmed that diabetes had been successfully induced in the experimental rats (Table 1, Fig. 1 and 2). Administration of resveratrol had no significant effect on blood glucose concentration with levels remaining $2 \cdot 8$ times higher in the $\mathrm{STZ}+$ Res rats $v$. the control group (Table 1). STZ + Res rats showed a significant increase in water consumption and decrease in body mass compared with the STZ animals from day 14 to 35 of the treatment period (Fig. 1 and 2). There were no differences in water intake and body mass between the STZ and the STZ + Res groups by the end of the study period (days 42-56) (Fig. 1 and 2).

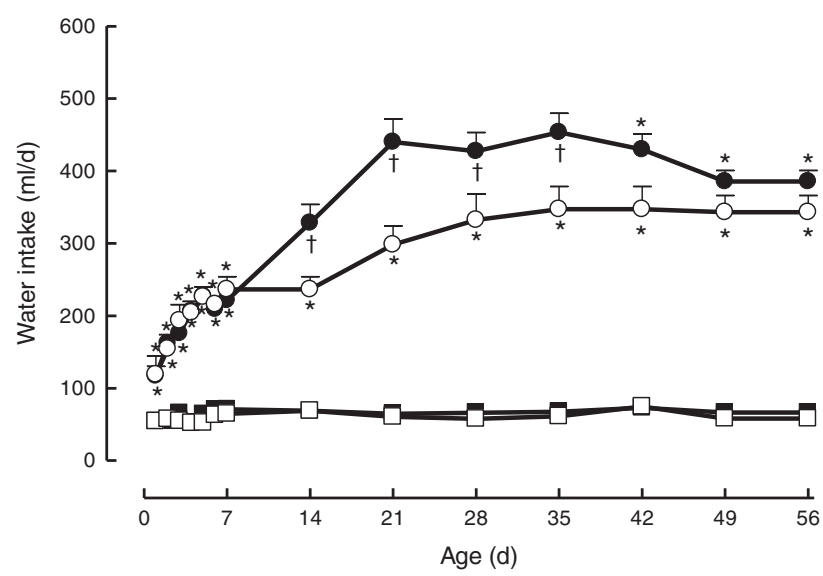

Fig. 1. Weekly water consumption for control (WIS ( $\square-n, n$ 8), control + resveratrol (WIS + Res (-,$- \quad n$ 8), streptozotocin (STZ $(-\bigcirc-n 7)$ and $\mathrm{STZ}+$ resveratrol $(\mathrm{STZ}+\operatorname{Res}(--, n 7)$ groups. Values are means, with their standard errors. ${ }^{*} P<0.05 \mathrm{v}$. WIS, $\dagger P<0.05 \mathrm{v}$. STZ. WIS, Wistar.

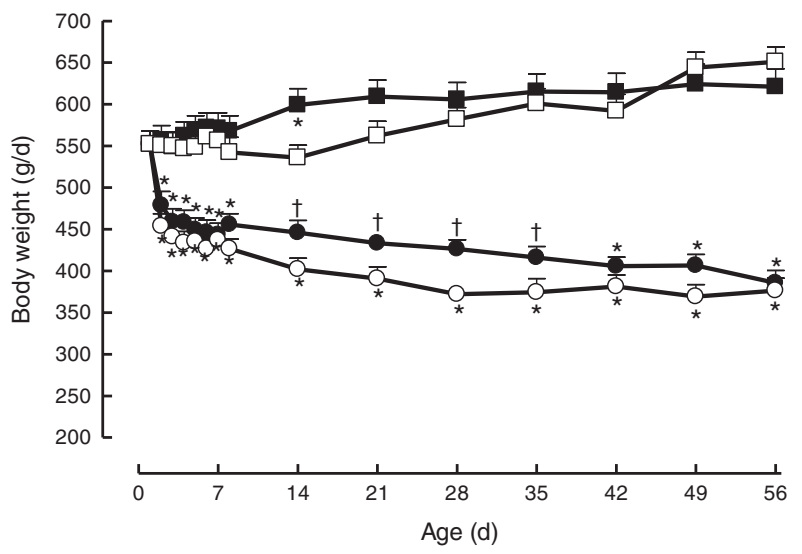

Fig. 2. Weekly body weight for control (WIS $(-\square-, n$ 8), control + resveratrol (WIS + Res (-,$n$ 8), streptozotocin (STZ (-O-, $n$ 7) and $\mathrm{STZ}+$ resveratrol $(\mathrm{STZ}+\operatorname{Res}(--, n 7)$ groups. Values are means, with their standard errors. ${ }^{*} P<0.05 v$. WIS, $† P<0.05 v$. STZ. WIS, Wistar.

Table 1. Physiological and biochemical parameters following resveratrol (Res) administration to control (WIS + Res) and diabetic (STZ + Res) rats (Mean values with their standard errors)

\begin{tabular}{|c|c|c|c|c|c|c|c|c|}
\hline \multirow[b]{2}{*}{ Parameters } & \multicolumn{2}{|c|}{ WIS ( $n$ 8) } & \multicolumn{2}{|c|}{ WIS + Res ( $n$ 8) } & \multicolumn{2}{|c|}{$\mathrm{STZ}(n 7)$} & \multicolumn{2}{|c|}{$\mathrm{STZ}+\operatorname{Res}(n 7)$} \\
\hline & Mean & SEM & Mean & SEM & Mean & SEM & Mean & SEM \\
\hline Plasma glucose (mmol/l) & $10 \cdot 93$ & 1.04 & $11 \cdot 33$ & 1.43 & $30 \cdot 60^{*}$ & 2.02 & $31 \cdot 10^{*}$ & $2 \cdot 82$ \\
\hline Left ventricular mass (mg/g body mass) & 1.66 & 0.07 & 1.90 & 0.09 & $2 \cdot 15^{*}$ & $0 \cdot 10$ & $2 \cdot 36^{*}$ & 0.09 \\
\hline Right ventricular mass (mg/g body mass) & 0.37 & 0.03 & 0.44 & 0.04 & 0.48 & 0.04 & 0.52 & 0.03 \\
\hline Kidney mass (mg/gram body mass) & 2.52 & 0.09 & 2.66 & 0.07 & $5 \cdot 01^{*}$ & $0 \cdot 16$ & $5 \cdot 20^{*}$ & 0.19 \\
\hline Systolic blood pressure (mmHg) & $122 \cdot 70$ & $6 \cdot 71$ & $129 \cdot 63$ & $5 \cdot 35$ & $123 \cdot 80$ & 3.41 & $129 \cdot 63$ & $5 \cdot 35$ \\
\hline Developed pressure (mmHg) & 113.00 & $7 \cdot 31$ & $96 \cdot 00$ & $6 \cdot 52$ & $63 \cdot 83^{*}$ & $8 \cdot 15$ & $81 \cdot 00^{\star}$ & $2 \cdot 77$ \\
\hline Diastolic stiffness (K dimensionless) & $22 \cdot 51$ & 0.71 & $20 \cdot 71$ & $1 \cdot 76$ & $15 \cdot 38^{\star}$ & 0.84 & $22 \cdot 29 \dagger$ & 0.87 \\
\hline$+d P / d T_{\max }(\mathrm{mmHg} / \mathrm{s})$ & $2170 \cdot 20$ & $155 \cdot 39$ & $1887 \cdot 60$ & $69 \cdot 42$ & $1237 \cdot 17^{*}$ & $158 \cdot 68$ & $1425 \cdot 00^{\star}$ & $57 \cdot 06$ \\
\hline$-d P / d T_{\max }(\mathrm{mmHg} / \mathrm{s})$ & $-1358 \cdot 80$ & 131.90 & $-1121 \cdot 80$ & 52.06 & $-672 \cdot 00^{\star}$ & $110 \cdot 45$ & $-833 \cdot 20^{\star}$ & $43 \cdot 11$ \\
\hline Heart rate (beats/min) & $448 \cdot 50$ & $26 \cdot 18$ & $479 \cdot 25$ & 11.98 & $363 \cdot 20^{*}$ & $14 \cdot 88$ & $380 \cdot 0^{*}$ & $10 \cdot 7$ \\
\hline Tactile allodynia (g) & $17 \cdot 10$ & 0.69 & $18 \cdot 63$ & 0.71 & $6 \cdot 33^{*}$ & 0.71 & $10 \cdot 17 \dagger$ & 0.31 \\
\hline
\end{tabular}

WIS, Wistar; STZ, streptozotocin

${ }^{*} P<0.05$ v. WIS, $† P<0.05$ v. STZ. 


\section{Neuropathic pain}

Diabetic rats developed significant tactile allodynia with the response threshold occurring at $6 \mathrm{~g}$ of force compared with $17 \mathrm{~g}$ in the control rats (Table 1). Resveratrol therapy significantly improved the development of tactile allodynia, increasing the withdrawal threshold to $10 \mathrm{~g}$ (Table 1).

\section{Haemodynamic assessment}

HR was significantly lower in the diabetic rats compared with the control animals and was not altered by resveratrol treatment (Table 1). SBP was not significantly different among any of the treatment groups. DM led to left ventricular and kidney hypertrophy, and this was not prevented by resveratrol (Table 1). Right ventricular mass was similar for all groups (Table 1).

\section{Vascular reactivity in isolated thoracic aortic rings}

Induction of DM and the administration of resveratrol increased vascular responsiveness to noradrenergic-mediated contractions

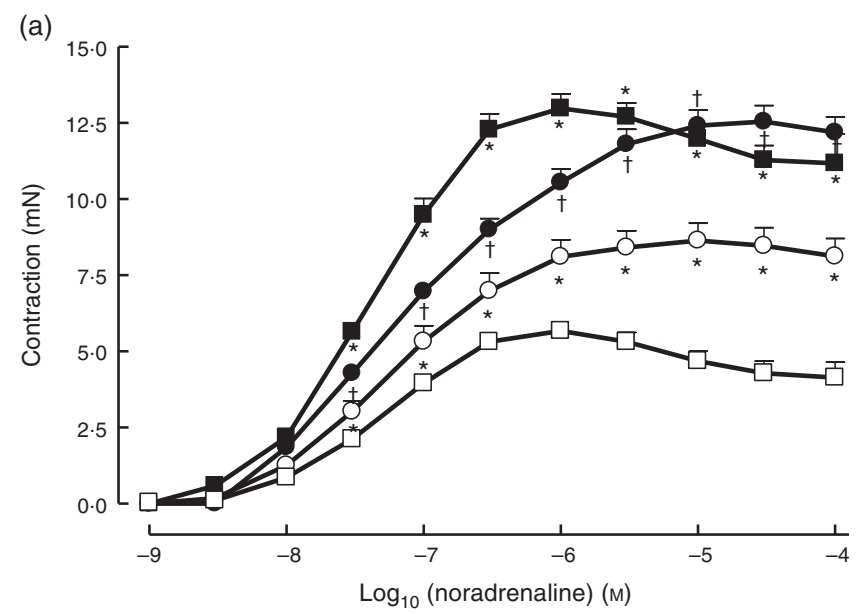

(Fig. 3(a)). Diabetic rats also had impaired endothelialdependent relaxation, an observation that was improved by resveratrol administration (Fig. 3(b)). Resveratrol therapy significantly enhanced endothelium-independent relaxation for both the STZ+Res and the WIS + Res groups (Fig. 3(c)). There were no significant differences in $\log _{10} \mathrm{EC}_{50}$ and hillslope values for noradrenaline, acetylcholine and sodium nitroprusside (Table 2). Endothelium-independent relaxation normalised to percentage inhibition of the contraction induced by noradrenaline showed reduced vascular responsiveness in diabetic animals, and this was not reversed by resveratrol (Fig. 4(a)). Endothelium-independent relaxation responses normalised to noradrenaline contraction demonstrated no significant differences among the treatment groups (Fig. 4(b)).

\section{Ex vivo left ventricular function}

Diastolic stiffness was significantly reduced in the untreated diabetic rats compared with the control groups but was normalised by resveratrol therapy (Table 1). Ventricular contractility $(+d P / d t)$, relaxation $(-d P / d t)$ and developed pressure
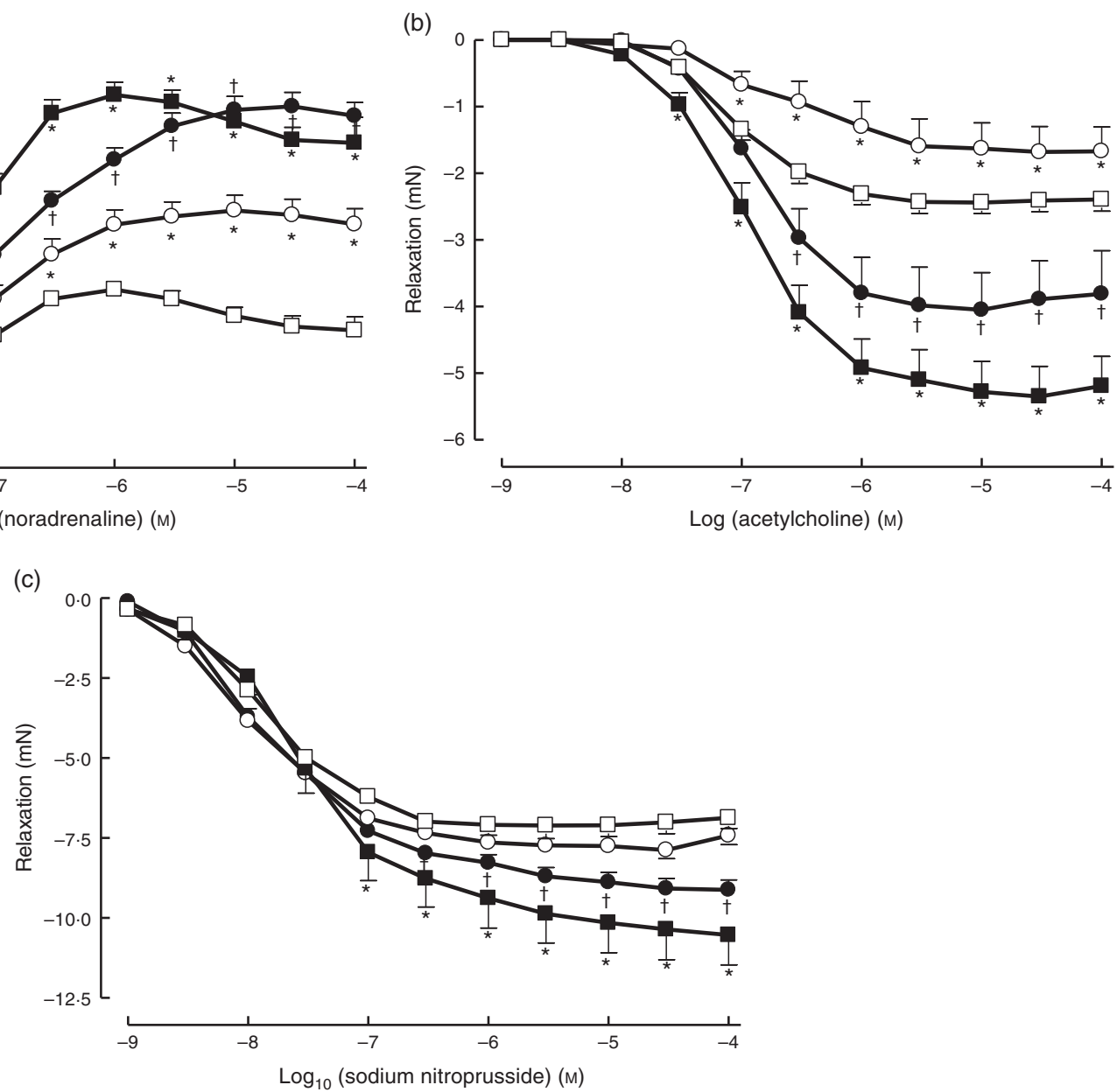

Fig. 3. (a) Cumulative concentration response to noradrenaline in isolated thoracic aortic rings from control (WIS $(-\square-, n 8)$, control + resveratrol (WIS + Res $(-\square$, $n$ 8), streptozotocin (STZ $\left(--_{-}, n 7\right)$ and STZ + resveratrol (STZ + Res $(--, n 7)$ groups. Values are means, with their standard errors. ${ }^{*} P<0.05 \mathrm{v}$. WIS, $\dagger P<0.05$ $v$ v. STZ. (b) Cumulative concentration response to acetylcholine in isolated noradrenaline pre-contracted thoracic aortic rings from WIS $(n 8)$, WIS + Res $(n 8)$, STZ $(n 7)$ and $\mathrm{STZ}+\operatorname{Res}(n 7)$ groups. (c) Cumulative concentration response to sodium nitroprusside in isolated noradrenaline pre-contracted thoracic aortic rings from WIS ( $n$ 8), WIS + Res ( $n$ 8), STZ ( $n$ 7) and STZ+Res $(n$ 7) groups. WIS, Wistar. 
Table 2. $\log _{10} \mathrm{EC}_{50}$ and hillslope values in isolated thoracic aortic rings following resveratrol (Res) administration to control (WIS + Res) and diabetic (STZ+Res) rats

(Mean values with their standard errors)

\begin{tabular}{|c|c|c|c|c|c|c|c|c|}
\hline \multirow[b]{2}{*}{ Parameters } & \multicolumn{2}{|c|}{ WIS $(n 8)$} & \multicolumn{2}{|c|}{ WIS + Res $(n 8)$} & \multicolumn{2}{|c|}{$\mathrm{STZ}(n 7)$} & \multicolumn{2}{|c|}{$\mathrm{STZ}+\operatorname{Res}(n 7)$} \\
\hline & Mean & SEM & Mean & SEM & Mean & SEM & Mean & SEM \\
\hline Noradrenaline $\left(\log _{10} \mathrm{EC}_{50}\right)$ & -7.326 & 0.1406 & -7.411 & 0.09197 & $-7 \cdot 211$ & 0.1474 & -7.072 & 0.08836 \\
\hline Acetylcholine $\left(\log _{10} \mathrm{EC}_{50}\right)$ & $-6 \cdot 7870$ & 0.34290 & -6.905 & 0.2077 & $-6 \cdot 840$ & 0.2335 & -6.858 & 0.2598 \\
\hline Sodium nitroprusside $\left(\log _{10} \mathrm{EC}_{50}\right)$ & $-7 \cdot 682$ & 0.2355 & $-7 \cdot 430$ & 0.2426 & -7.827 & 0.07111 & -7.681 & 0.07779 \\
\hline Noradrenaline (hillslope) & 1.212 & 0.4123 & $1 \cdot 181$ & 0.2581 & 0.9684 & 0.2793 & 0.7912 & 0.1126 \\
\hline Acetylcholine (hillslope) & -0.6771 & 0.3427 & -1.234 & 0.6532 & -1.417 & 0.9694 & -1.333 & 0.9545 \\
\hline Sodium nitroprusside (hillslope) & -0.7691 & 0.2934 & -0.8882 & 0.3930 & -0.9764 & $0 \cdot 1412$ & -0.8699 & 0.1223 \\
\hline
\end{tabular}

WIS, Wistar; STZ, streptozotocin.

(a)

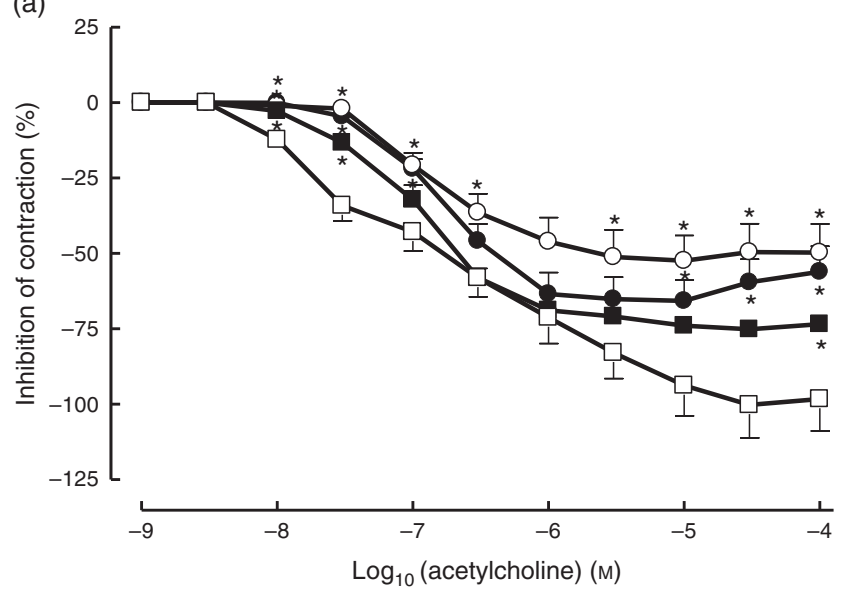

(b)

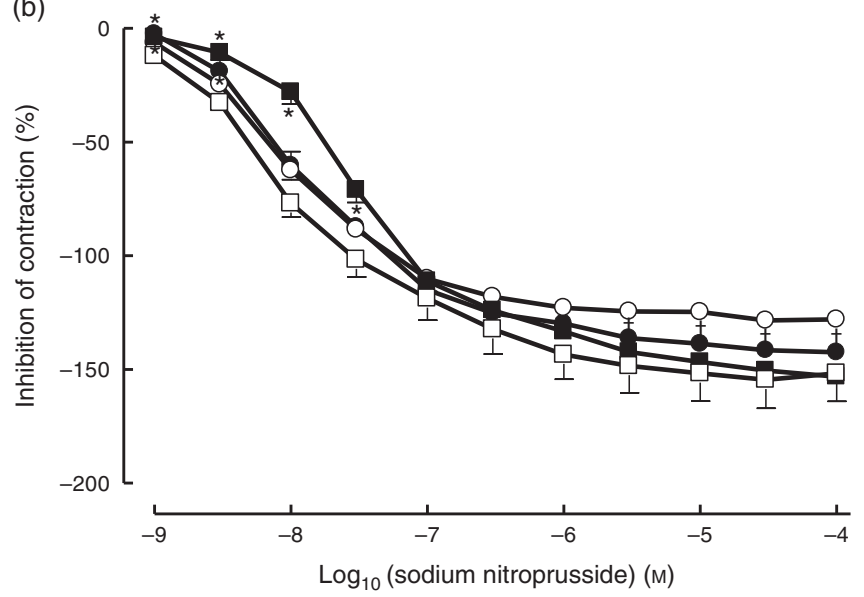

Fig. 4. (a) Cumulative concentration response to acetylcholine as a percentage inhibition of the contraction induced by noradrenaline in isolated noradrenaline precontracted thoracic aortic rings from control (WIS $(-\square-, n 8)$, control + resveratrol (WIS + Res $(-\square, n 8)$, streptozotocin (STZ ( $-\bigcirc-, n 7)$ and STZ + resveratrol $\left(\mathrm{STZ}+\operatorname{Res}(-, n 7)\right.$ groups. Values are means, with their standard errors represented by vertical bars. ${ }^{*} P<0.05 v$. WIS. (b) Cumulative concentration response to sodium nitroprusside as a percentage inhibition of the contraction induced by noradrenaline in isolated noradrenaline pre-contracted thoracic aortic rings normalised to from WIS ( $n$ 8), WIS + Res ( $n$ 8), STZ $(n 7)$ and STZ + Res $(n 7)$ groups. Values are means, with their standard errors. ${ }^{*} P<0.05 v$. WIS, $† P<0.05 v$. STZ. WIS, Wistar.

were substantially decreased in the diabetic animals, and this was not significantly altered by resveratrol therapy (Table 1 ).

\section{Discussion}

This study aimed to assess whether resveratrol administration to diabetic animals, at a dose that can be reasonably achieved with supplementation, could produce improvements in cardiovascular function

Resveratrol supplementation in old diabetic animals successfully inhibited increased nerve sensitivity. This attenuation of diabetic neuropathy likely reflects the ROS scavenging capabilities of resveratrol, preventing neuronal cell death, as reported previously ${ }^{(48-50)}$

STZ-induced DM is known to increase oxidative stress and subsequently impair endothelial and smooth muscle function in isolated thoracic aortas ${ }^{(51-53)}$. Consistent with these findings, we observed significantly reduced endothelium-dependent and endothelium-independent relaxation in thoracic aortic rings isolated from STZ rats. Supplementation with resveratrol substantially improved vasorelaxation and increased maximal contractile response of the blood vessels. These results reflect previous reports that resveratrol can improve vaso-relaxant and vaso-contractile capacity as a result of its ability to reduce free radical production ${ }^{(16,19,46,52-55)}$.

Relaxation responses normalised to percentage inhibition of the contraction induced by noradrenaline also showed impaired endothelial function in the STZ rats; however, there was no effect of resveratrol administration. There were also no 1differences overall between any of the groups when endothelium-independent relaxation responses were standardised to inhibition of noradrenaline contraction. Similarly, $\log _{10} \mathrm{EC}_{50} \mathrm{~s}$ and hillslope values for noradrenaline, acetylcholine or sodium nitroprusside were similar for all treatment groups. Ultimately, these findings suggest that the differences observed in maximal contraction and relaxation responses in STZ- and/or resveratrol-treated animals were not due to differences in the pharmacological response of each tissue but due to changes in the physiology of the vasculature itself.

Data from human clinical trials examining the effectiveness of resveratrol in attenuating diabetes-induced CVD indicate that the positive outcomes of resveratrol administration seen in animal studies are not entirely translatable to humans. An investigation into the effects of short-term ( 4 week) resveratrol 
$(1.5 \mathrm{~g} / \mathrm{d})$ treatment in obese, mildly insulin-resistant men found that resveratrol had no significant effect on SBP and diastolic blood pressure, inflammatory biomarkers, insulin sensitivity or HbA1c levels ${ }^{(56)}$. A non-significant effect of resveratrol on SBP in type 2 diabetic patients has also been reported ${ }^{(57)}$. A recent meta-analysis concluded that resveratrol produced small but statistically significant improvements in SBP, creatinine and HbA1c in subjects with type $2 \mathrm{DM}$ but, on average, had no effect on fasting glucose, insulin, diastolic blood pressure, cholesterol or TAG levels ${ }^{(58)}$.

Similar to these findings, we observed that supplementation with resveratrol was unable to lower blood glucose levels, prevent left ventricular remodelling or improve left ventricular pump function in old, obese, diabetic rats. These results are in contrast to other studies that have found that resveratrol prevented left ventricular hypertrophy and normalised left ventricular compliance in 8-week-old diabetic, deoxycorticosterone acetate (DOCA)-salt and spontaneously hypertensive rats $^{(46,52,59)}$. Likewise, administering resveratrol to 8-10-week-old diabetic rats has been reported to decrease plasma glucose levels by approximately $20 \%{ }^{(34,60)}$.

The discrepancy between these results and those of the present study may be due to the different age groups of the rats used in each experiment (i.e. 8-10-week $v$. 6-month-old rats). Ageing in Wistar rats has been associated with insulin resistance, meaning that the older rats used in this study could have negatively influenced the cardiac response and hypoglycaemic effects of resveratrol $^{(41,42)}$. Nevertheless, in a previous study using 8-week-old rats, we also observed no significant effect of resveratrol on plasma glucose levels when administered at the same dose of $2 \mathrm{mg} / \mathrm{kg}$ per $\mathrm{d}$ for 8 weeks ${ }^{(46)}$. Considering that the other investigations administered resveratrol at doses of $0.5 \mathrm{mg} / \mathrm{kg}$ thrice daily for 2 weeks and $0.75 \mathrm{mg} / \mathrm{kg}$ thrice daily for 8 weeks, it is possible that the frequency of dosing (i.e. one $v$. multiple doses per $\mathrm{d}$ ) could have influenced resveratrol's glucose-lowering properties ${ }^{(34)}$. Older animals also show negative age-related alterations in cardiovascular function and poorer ROS scavenging capacity ${ }^{(61,62)}$. In this study, these changes in antioxidant ability could have posed an additional pathophysiological challenge for resveratrol to overcome.

The findings of the present investigation match those of human studies that indicate that the animal model used here (i.e. 6-month old, obese, diabetic rats) may be a more accurate representation of the ageing human patient with type 1 or type 2 DM. These similarities also mean that the lack of improvement in cardiac function and glucose levels observed in the STZ + Res animals was not so unexpected. Ultimately, there is insufficient evidence to fully support the viability of resveratrol as a nutritional supplement to improve metabolic health ${ }^{(56-66)}$.

\section{Conclusion}

Although resveratrol was successful in preserving vasocontractile and nerve functionality in this study, in reality, supplementation with resveratrol at a dose achievable with commercially available supplements may not be a viable all-round treatment for DM. The cardioprotective effects of resveratrol observed in this investigation were not as extensive as those reported by previous studies and may be associated with the age and degree of obesity in these rats. The similarity between the findings of the present investigation and human studies indicates that the animal model used in these experiments (i.e. 6-month old, obese, diabetic rats) may be a more accurate representation of type $1 \mathrm{DM}$, and aspects of type $2 \mathrm{DM}$, in older humans.

\section{Acknowledgements}

Funding for this project was provided by Central Queensland University's (CQU) Office of Research Services. CQU's Office of Research Services had no role in the design, analysis or writing of this article.

H. E. P., A. S. F. formulated the research questions, designed the research study and performed the research; H. E. P., R. K. V., J. C. I. analysed the data; R. K. V., J. C. I. drafted the paper; R. K. V., A. S. F., J. C. I. revised the paper.

The authors declare that there are no conflicts of interest.

\section{References}

1. Elbe H, Vardi N, Esrefoglu M, et al. (2015) Amelioration of streptozotocin-induced diabetic nephropathy by melatonin, quercetin, and resveratrol in rats. Hum Exp Toxicol 34, 100-113.

2. Nishikawa T, Edelstein D, Du XL, et al. (2000) Normalizing mitochondrial superoxide production blocks three pathways of hyperglycaemic damage. Nature 404, 787-790.

3. Robertson RP \& Harmon JS (2006) Diabetes, glucose toxicity, and oxidative stress: a case of double jeopardy for the pancreatic islet beta cell. Free Radic Biol Med 41, 177-184.

4. Schlotthauer G, Gamero LG, Torres ME, et al. (2006) Modeling, identification and nonlinear model predictive control of type I diabetic patient. Med Eng Phys 28, 240-250.

5. Coskun O, Ocakci A, Bayraktaroglu T, et al. (2004) Exercise training prevents and protects streptozotocin-induced oxidative stress and beta-cell damage in rat pancreas. Tokai J Exp Clin Med 203, 145-154.

6. Soufi FG, Mohammad-Nejad D \& Ahmadieh H (2012) Resveratrol improves diabetic retinopathy possibly through oxidative stress-nuclear factor kappaB-apoptosis pathway. Pharmacol Rep 64, 1505-1514.

7. Brownlee M (2005) The pathobiology of diabetic complications: a unifying mechanism. Diabetes 54, 1615-1625.

8. Cai L \& Kang YJ (2001) Oxidative stress and diabetic cardiomyopathy: a brief review. Cardiovasc Toxicol 1, 181-193.

9. Ceriello A, Mercuri F, Quagliaro L, et al. (2001) Detection of nitrotyrosine in the diabetic plasma: evidence of oxidative stress. Diabetologia 44, 834-838.

10. Obrosova IG, Mabley JG, Zsengeller Z, et al. (2005) Role for nitrosative stress in diabetic neuropathy: evidence from studies with a peroxynitrite decomposition catalyst. FASEB J 19, 401-403.

11. Cade WT (2008) Diabetes-related microvascular and macrovascular diseases in the physical therapy setting. Phys Ther 88, 1322-1335.

12. Voulgari C, Papadogiannis D \& Tentolouris N (2010) Diabetic cardiomyopathy: from the pathophysiology of the cardiac myocytes to current diagnosis and management strategies. Vasc Health Risk Manag 6, 883-903.

13. Makino N, Maeda T, Sugano M, et al. (2005) High serum TNF-alpha level in type 2 diabetic patients with microangiopathy is associated with eNOS down-regulation and apoptosis in endothelial cells. J Diabetes Complications 19, 347-355. 
14. Tabish SA (2007) Is diabetes becoming the biggest epidemic of the twenty-first century? Int J Health Sci (Qassim) 1, V-VIII.

15. Bauters C, Lamblin N, McFadden EP, et al. (2003) Influence of diabetes mellitus on heart failure risk and outcome. Cardiovasc Diabetol 2, 1

16. Bors W \& Michel C (2002) Chemistry of the antioxidant effect of polyphenols. Ann N Y Acad Sci 957, 57-69.

17. Hung LM, Chen JK, Huang SS, et al. (2000) Cardioprotective effect of resveratrol, a natural antioxidant derived from grapes. Cardiovasc Res 47, 549-555.

18. Miller NJ \& Paganga G (1998) Antioxidant activity of low-density lipoprotein. Methods Mol Biol 108, 325-335.

19. Ou HC, Chou FP, Sheen HM, et al. (2006) Resveratrol, a polyphenolic compound in red wine, protects against oxidized LDL-induced cytotoxicity in endothelial cells. Clin Chim Acta 364, 196-204

20. Hung LM, Su MJ \& Chen JK (2004) Resveratrol protects myocardial ischemia-reperfusion injury through both NO-dependent and NO-independent mechanisms. Free Radic Biol Med 36, 774-781.

21. Oak MH, El Bedoui J \& Schini-Kerth VB (2005) Antiangiogenic properties of natural polyphenols from red wine and green tea. J Nutr Biochem 16, 1-8.

22. Olas B \& Wachowicz B (2002) Resveratrol and vitamin C as antioxidants in blood platelets. Thromb Res 106, 143-148.

23. Olson ER, Naugle JE, Zhang X, et al. (2005) Inhibition of cardiac fibroblast proliferation and myofibroblast differentiation by resveratrol. Am J Physiol Heart Circ Physiol 288 H1131-H1138.

24. Raj P, Louis XL, Thandapilly SJ, et al. (2014) Potential of resveratrol in the treatment of heart failure. Life Sci 95, 63-71.

25. Wallerath T, Deckert G, Ternes T, et al. (2002) Resveratrol, a polyphenolic phytoalexin present in red wine, enhances expression and activity of endothelial nitric oxide synthase. Circulation 106, 1652-1658.

26. Cao Z \& Li Y (2004) Potent induction of cellular antioxidants and phase 2 enzymes by resveratrol in cardiomyocytes: protection against oxidative and electrophilic injury. Eur J Pharmacol 489, 39-48.

27. Brasnyo P, Molnar GA, Mohas M, et al. (2011) Resveratrol improves insulin sensitivity, reduces oxidative stress and activates the Akt pathway in type 2 diabetic patients. Br J Nutr 106, 383-389.

28. Bradamante S, Barenghi L \& Villa A (2004) Cardiovascular protective effects of resveratrol. Cardiovasc Drug Rev 22, 169-188.

29. Mokni M, Limam F, Elkahoui S, et al. (2007) Strong cardioprotective effect of resveratrol, a red wine polyphenol, on isolated rat hearts after ischemia/reperfusion injury. Arch Biochem Biophys 457, 1-6.

30. Pignatelli P, Ghiselli A, Buchetti B, et al. (2006) Polyphenols synergistically inhibit oxidative stress in subjects given red and white wine. Atherosclerosis 188, 77-83.

31. Schmitt CA \& Dirsch VM (2009) Modulation of endothelial nitric oxide by plant-derived products. Nitric Oxide 21, 77-91.

32. Schriever C, Pendland SL \& Mahady GB (2003) Red wine, resveratrol, Chlamydia pneumoniae and the French connection. Atherosclerosis 171, 379-380.

33. Shen M, Jia GL, Wang YM, et al. (2006) Cardioprotective effect of resvaratrol pretreatment on myocardial ischemiareperfusion induced injury in rats. Vascul Pharmacol $\mathbf{4 5}$ 122-126.

34. Su HC, Hung LM \& Chen JK (2006) Resveratrol, a red wine antioxidant, possesses an insulin-like effect in streptozotocininduced diabetic rats. Am J Physiol Endocrinol Metab 290 , E1339-E1346.
35. Semba RD, Ferrucci L, Bartali B, et al. (2014) Resveratrol levels and all-cause mortality in older community-dwelling adults. JAMA Intern Med 174, 1077-1084.

36. Ghanim H, Sia CL, Abuaysheh S, et al. (2010) An antiinflammatory and reactive oxygen species suppressive effects of an extract of Polygonum cuspidatum containing resveratrol. J Clin Endocrinol Metab 95, E1-E8.

37. Movahed A, Nabipour I, Lieben Louis X, et al. (2013) Antihyperglycemic effects of short term resveratrol supplementation in type 2 diabetic patients. Evid Based Complement Alternat Med 2013, 851267.

38. Bhatt JK, Thomas S \& Nanjan MJ (2012) Resveratrol supplementation improves glycemic control in type 2 diabetes mellitus. Nutr Res 32, 537-541.

39. Wei M, Ong L, Smith MT, et al. (2003) The streptozotocindiabetic rat as a model of the chronic complications of human diabetes. Heart Lung Circ 12, 44-50.

40. Gencoglu H, Tuzcu M, Hayirli A, et al. (2015) Protective effects of resveratrol against streptozotocin-induced diabetes in rats by modulation of visfatin/sirtuin-1 pathway and glucose transporters. Int J Food Sci Nutr 66 , 314-320.

41. Escriva F, Gavete ML, Fermin Y, et al. (2007) Effect of age and moderate food restriction on insulin sensitivity in Wistar rats: role of adiposity. I Endocrinol 194, 131-141.

42. Frutos MG-S, Fernández-Agulló T, Solís AJD, et al. (2007) Impaired central insulin response in aged Wistar rats: role of adiposity. Endocrinology 148, 5238-5247.

43. King AJ (2012) The use of animal models in diabetes research. Br J Pharmacol 166, 877-894.

44. Yamakawa T, Tanaka S, Tamura K, et al. (1995) Wistar fatty rat is obese and spontaneously hypertensive. Hypertension $\mathbf{2 5}$, 146-150.

45. Agarwal B, Campen MJ, Channell MM, et al. (2013) Resveratrol for primary prevention of atherosclerosis: clinical trial evidence for improved gene expression in vascular endothelium. Int J Cardiol 166, 246-248.

46. Vella RK, Pullen C, Coulson FR, et al. (2015) Resveratrol prevents cardiovascular complications in the SHR/STZ rat by reductions in oxidative stress and inflammation. Biomed Res Int 2015, 918123

47. Pullen C, Vella R \& Fenning A (2009) The prevention of maladaptive cardiovascular electrophysiological changes in animal models of hypertension and diabetes by resveratrol. Heart Lung Circ 18, S309-S310.

48. Mohamed HE, El-Swefy SE, Hasan RA, et al. (2014) Neuroprotective effect of resveratrol in diabetic cerebral ischemic-reperfused rats through regulation of inflammatory and apoptotic events. Diabetol Metab Syndr 6, 88

49. Sandireddy R, Yerra VG, Areti A, et al. (2014) Neuroinflammation and oxidative stress in diabetic neuropathy: futuristic strategies based on these targets. Int $J$ Endocrinol 2014, 10.

50. Sharma S, Chopra K \& Kulkarni SK (2007) Effect of insulin and its combination with resveratrol or curcumin in attenuation of diabetic neuropathic pain: participation of nitric oxide and TNF-alpha. Phytother Res 21, 278-283.

51. Silan C (2008) The effects of chronic resveratrol treatment on vascular responsiveness of streptozotocin-induced diabetic rats. Biol Pharm Bull 31, 897-902.

52. Chan V, Fenning A, Iyer A, et al. (2011) Resveratrol improves cardiovascular function in DOCA-salt hypertensive rats. Curr Pharm Biotechnol 12, 429-436.

53. Oelze M, Kröller-Schön S, Welschof P, et al. (2014) The sodium-glucose co-transporter 2 inhibitor empagliflozin improves diabetes-induced vascular dysfunction in the 
streptozotocin diabetes rat model by interfering with oxidative stress and glucotoxicity. PLOS ONE 9, e112394.

54. Labinskyy N, Csiszar A, Veress G, et al. (2006) Vascular dysfunction in aging: potential effects of resveratrol, an antiinflammatory phytoestrogen. Curr Med Chem 13, 989-996.

55. Pignatelli P, Di Santo S, Buchetti B, et al. (2006) Polyphenols enhance platelet nitric oxide by inhibiting protein kinase C-dependent NADPH oxidase activation: effect on platelet recruitment. FASEB J 20, 1082-1089.

56. Poulsen MM, Vestergaard PF, Clasen BF, et al. (2013) High-dose resveratrol supplementation in obese men: an investigator-initiated, randomized, placebo-controlled clinical trial of substrate metabolism, insulin sensitivity, and body composition. Diabetes 62, 1186-1195.

57. Liu Y, Ma W, Zhang P, et al. (2015) Effect of resveratrol on blood pressure: a meta-analysis of randomized controlled trials. Clin Nutr 34, 27-34.

58. Hausenblas HA, Schoulda JA \& Smoliga JM (2015) Resveratrol treatment as an adjunct to pharmacological management in type 2 diabetes mellitus - systematic review and metaanalysis. Mol Nutr Food Res 59, 147-159.

59. Thirunavukkarasu M, Penumathsa SV, Koneru S, et al. (2007) Resveratrol alleviates cardiac dysfunction in streptozotocininduced diabetes: role of nitric oxide, thioredoxin, and heme oxygenase. Free Radic Biol Med 43, 720-729.
60. Chen KH, Cheng ML, Jing YH, et al. (2011) Resveratrol ameliorates metabolic disorders and muscle wasting in streptozotocin-induced diabetic rats. Am J Physiol Endocrinol Metab 301, E853-E863.

61. Dai D-F \& Rabinovitch PS (2009) Cardiac aging in mice and humans: the role of mitochondrial oxidative stress. Trends Cardiovasc Med 19, 213-220.

62. Braidy N, Guillemin GJ, Mansour H, et al. (2011) Age related changes in NAD+ metabolism oxidative stress and Sirt1 activity in Wistar rats. PLOS ONE 6, e19194.

63. Crandall JP, Oram V, Trandafirescu G, et al. (2012) Pilot study of resveratrol in older adults with impaired glucose tolerance. J Gerontol A Biol Sci Med Sci 67, 1307-1312.

64. De Groote D, Van Belleghem K, Deviere J, et al. (2012) Effect of the intake of resveratrol, resveratrol phosphate, and catechin-rich grape seed extract on markers of oxidative stress and gene expression in adult obese subjects. Ann Nutr Metab 61, 15-24.

65. Timmers S, Hesselink MK \& Schrauwen P (2013) Therapeutic potential of resveratrol in obesity and type 2 diabetes: new avenues for health benefits? Ann N Y Acad Sci 1290, 83-89.

66. Wong RH, Howe PR, Buckley JD, et al. (2011) Acute resveratrol supplementation improves flow-mediated dilatation in overweight/obese individuals with mildly elevated blood pressure. Nutr Metab Cardiovasc Dis 21, 851-856. 